\title{
Impact of pulsed electric field pre-treatment on nutritional and polyphenolic contents and bioactivities of light and dark brewer's spent grains
}

\author{
Author list \\ Bibha Kumari $^{\mathrm{a}, \mathrm{e}}$, Brijesh K Tiwari ${ }^{\mathrm{b}}$, Des Walsh ${ }^{\mathrm{c}}$, Tomás P Griffin ${ }^{\mathrm{d}}$, Nahidul Islam ${ }^{\mathrm{d}}$, James G. Lyng ${ }^{\mathrm{e}}$, \\ Nigel P. Brunton ${ }^{\mathrm{e}}$, and Dilip K. Rai ${ }^{\mathrm{a}^{*}}$ \\ ${ }^{a}$ Department of Food Biosciences, Teagasc Food Research Centre Ashtown, Dublin, D15KN3K, Ireland \\ ${ }^{\mathrm{b}}$ Department of Food Biosciences, Teagasc Food Research Centre Ashtown, Dublin, D15KN3K, Ireland. \\ ${ }^{c}$ Department of Food Safety, Teagasc Food Research Centre Ashtown, Dublin, D15KN3K, Ireland. \\ ${ }^{\mathrm{d}}$ Regenerative Medicine Institute, National University of Ireland Galway, Galway, Ireland. \\ ${ }^{\mathrm{e}}$ Institute of Food and Health, University College Dublin, Belfield, Dublin, D04V1W8, Ireland.
}

Short Title: Chemical composition and biological activity of brewer's spent grain

\section{*Address for the corresponding author:}

Dr. Dilip Rai, Teagasc Food Research Centre Ashtown, Dublin, D15KN3K, Ireland.

Email: dilip.rai@teagasc.ie; Tel: +35318059569, Mobile: +353870991154. 


\begin{abstract}
Pulsed electric field (PEF) pre-treatment, at $2.8 \mathrm{kV} / \mathrm{cm}$ with 3000 pulses of $20 \mu$ sulse-width, was applied on the brewer's spent grains (BSG) followed by aqueous extraction at $55^{\circ} \mathrm{C}, 220 \mathrm{rpm}$ for $16 \mathrm{~h}$. PEF pre-treatment showed significantly increased yields $(\mathrm{p}<0.05)$ of carbohydrate, protein, starch and reducing sugar in extracts from dark BSG compared to untreated samples. Light BSG extracts had significantly higher $(\mathrm{p}<0.05)$ levels of free $\mathrm{D}$-glucose and total free amino acids $(18.5-33.3$ and 21-25 $\mathrm{mg} / \mathrm{g}$ dry weight extract (Dwe)), compared to dark extracts (5 and $1.2 \mathrm{mg} / \mathrm{g}$ Dwe) respectively). Dark BSG extracts showed significantly higher $(\mathrm{p}<0.05)$ total phenolics $(3.97-4.88 \mathrm{mg}$ GAE/g Dwe) compared to light BSG extracts (0.83-1.40 mg GAE/g Dwe). Furthermore, PEF treated light BSG showed higher antimicrobial activity with minimum inhibition concentration (MIC) of 50 and 25 $\mathrm{mg} / \mathrm{mL}$ against Salmonella typhimurium and Listeria monocytogenes, respectively compared to the untreated extracts $(>50 \mathrm{mg} / \mathrm{mL}$ ) with lowest MIC value of $1.56 \mathrm{mg} / \mathrm{mL}$ against Staphylococcus aureus. All the BSG extracts induced the release of pro-inflammatory cytokines (IL-1 $\beta$, IL-6, TNF- $\alpha$ ) and chemokines (IL-8, MCP-1 and MIP-1 $\alpha$ ) confirming immunomodulatory activity.
\end{abstract}

Keywords: Pulsed electric field, brewer's spent grain, antioxidant activity, antimicrobial activity, immunomodulatory activity. 


\section{Introduction}

Barley production in Europe for 2014 was 93.6 million tonnes and accounted for nearly two-third of the global production (FAOSTAT, 2015). Approximately one fifth of the cultivated barley in Europe is used by the brewing industries for beverage production (Marquer, 2010). Brewer's spent grain (BSG), a by-product of the brewing industry andaccounts for $85 \%$ of total brewing waste. BSG is generated at $20 \mathrm{~kg} / \mathrm{hL}$ of beer production resulting in 3.4 million tonnes of BSG generation annually in Europe (Lynch, Steffen, \& Arendt, 2016). Ireland generates about 160,000 tonnes of BSG from 8 million $\mathrm{hL}$ of beer production (FAOSTAT, 2015). BSG contains a number of components with potential for exploitation such as $\beta$-glucans, dietary fibres, hemicelluloses i.e. arabinoxylans and lignin, phenolic acids, bioactive proteins and carbohydrates (Connolly, Piggott, \& FitzGerald, 2013; McCarthy, O’Callaghan, Connolly, Piggott, FitzGerald, \& O’Brien, 2012; Waters, Jacob, Titze, Arendt, \& Zannini, 2012). Thus BSG can be exploited as a source of functional food ingredients, the market for which is estimated to reach ca. $€ 43$ billion globally by 2017 (Bonar, 2014). However, realising the potential of this resource depends on the availability of sustainable strategies for the recovery and isolation of these components. Conventional extraction methods are labour intensive, often expensive, and environmentally costly; thus to realise the potential of this resource there is a need for more sustainable alternative extraction technologies. For example a number other extraction techniques have been applied to BSG including microwave assisted extraction for polyphenols (Moreira, Morais, Barros, Delerue-Matos, \& Guido, 2012), ultrasound assisted extraction for proteins (Tang, Tian, He, Li, Hu, \& Li, 2010), arabinoxylans (Reis, Coelho, Coimbra, \& Abu-Ghannam, 2015), and flavonoids (Farcas, Tofana, Socaci, Scrob, Salanta, \& Pop, 2013). In addition pulsed electric field (PEF) assisted extraction has attracted significant interest as a means of extracting value from rest raw materials such as BSG. PEF enhances mass transfer rates by electroporation of cell membranes (Soliva-Fortuny, Balasa, Knorr, \& Martín-Belloso, 2009). When PEF is applied, several processing parameters (electric field, pulse shape, width and frequency, total treatment time, electrode configuration and temperature) have to be carefully tuned and several critical factors have to be considered in the design 183 to obtain efficient processes (Barba et al., 2015). 
The applications of PEF treatment for improving the extraction of proteins, phenolic compounds, carbohydrates, and isothiocyanates from various agro-industrial by-products have been recently reviewed by Kumari, Tiwari, Hossain, Brunton, and Rai (2017). Moreover, Barba, Mariutti, Bragagnolo, Mercadante, Barbosa-Cánovas, and Orlien (2017) reviewed current applications and new opportunities for the use of pulsed electric fields in food science and industry, whereas details of application of PEF for utilization of by-products in food and vegetable oil industry are outlined by Puértolas and Barba, (2016); Puértolas, Koubaa, and Barba (2016). In general PEF intensities ranging from $0.5-2 \mathrm{kV} / \mathrm{cm}$ are used for fresh materials whereas high dry matter containing materials require higher intensity e.g. $20 \mathrm{kV} / \mathrm{cm}$ (Boussetta, Soichi, Lanoisellé, \& Vorobiev, 2014). However to date, no study on the application of PEF for extraction of value added products from BSG has been reported. In the present study, we have investigated the effect of PEF treatment on the contents of bioactive constituents in dark and light BSG extracts as well as on their antioxidant, antimicrobial and immunomodulatory properties.

\section{Materials and methods}

\subsection{Materials and reagents}

Light BSG samples were provided by The 5 Lamps Brewery (Dublin, Ireland) whereas dark BSG was provided by Diageo Plc. Ltd., Dublin. Total starch and glucose measurement kits and $\beta$-glucan molecular weight (MW) standards were purchased from Megazyme, Wicklow, Ireland. All other chemicals, protein MW standards i.e. albumin monomer and dimer, carbonic anhydrase, cytochrome $\mathrm{C}$ and aprotinin, enzymes and HPLC-grade organic reagents were purchased from Sigma-Aldrich (Wicklow, Ireland).

\subsection{Sample preparation}

Immediately after collection BSG samples were blast frozen at $-40{ }^{\circ} \mathrm{C}$ for $2 \mathrm{~h}$, vacuum packed and stored at $-20{ }^{\circ} \mathrm{C}$ until needed for extraction purposes. A portion of the frozen BSG was subjected to freeze drying for $24 \mathrm{~h}$ in FD 80 freeze dryer (Cuddon Limited, Blenheim, New Zealand). Freeze dried samples were immediately powdered, vacuum packed and kept in $-20{ }^{\circ} \mathrm{C}$ for total dietary fibre analysis. 


\subsection{Preparation of crude BSG extracts}

\subsubsection{Solid-Liquid extraction (SLE)}

Conventional SLE on thawed light BSG ( 27\% dry matter) and dark BSG ( 30\% dry matter) using distilled water was adapted from the optimised method by Gangopadhyay et al. 2015. Briefly, $35 \mathrm{~g}$ (wet basis) each of light and dark BSG were extracted with $30 \mathrm{~g}$ and $40 \mathrm{~g}$ of distilled water respectively (ratio of $1: 6 \mathrm{w} / \mathrm{w}$ on dry basis) in an incubator shaker at $55{ }^{\circ} \mathrm{C}, 220 \mathrm{rpm}$ for $16 \mathrm{~h}$. The resulting slurries were centrifuged at $5000 \mathrm{~g}$ for $12 \mathrm{~min}$ to separate the supernatant. The supernatants were immediately filtered using Whatman ${ }^{\circledR}$ glass microfiber filters and stored at $-20{ }^{\circ} \mathrm{C}$ until further analysis. The obtained crude extracts were termed as light BSG control (LBC) and dark BSG control (DBC).

\subsubsection{Pulsed electric field (PEF) assisted extraction}

Light and dark BSG (35 g, wet basis) samples mixed with $30 \mathrm{~g}$ and $40 \mathrm{~g}$ distilled water (ratio of 1:6 w/w on dry basis) respectively, were subjected to PEF treatment using ELCRACK® HVP 5 unit (DIL, Quakenbrück, Germany) having a max output voltage of $25 \mathrm{kV}$ and generating square waveform pulses with applied frequency of $10 \mathrm{~Hz}$ in the bipolar mode. The pre-treatment was conducted in a parallel stainless steel electrode chamber with a gap of $4 \mathrm{~cm}$ and a surface area of 16 $\mathrm{cm}^{2}$. Peak pulse voltage was $11.2 \mathrm{kV}$ resulting in field strength of $2.8 \mathrm{kV} / \mathrm{cm}$. A total of 3000 pulses with a pulse width of $20 \mu$ s were applied resulting in an exposure time of $60 \mathrm{sec}$ (pulse width x no. of pulses). The maximum temperature of BSG samples before and after the treatments was $23.5 \pm 0.5^{\circ} \mathrm{C}$ and $50.0 \pm 5.0{ }^{\circ} \mathrm{C}$, respectively. The PEF pre-treated samples were then subjected to SLE extraction as described in Section 2.3.1. The obtained extracts were termed as light BSG PEF (LBP) and dark BSG PEF (DBP) and stored at $-20^{\circ} \mathrm{C}$ until further analysis.

\subsection{Compositional analysis}

\subsubsection{Raw material (light and dark BSG)}

The freshly frozen BSG samples stored at $-20{ }^{\circ} \mathrm{C}$ were thawed and kept at $4{ }^{\circ} \mathrm{C}$ prior to use for proximate compositional analysis. Total moisture and fat content were determined using a Smart $\operatorname{Trac}^{\mathrm{TM}}$ analyser (CEM Corporation, Matthews, North Carolina, USA) based on NMR principle and protein content was determined using a nitrogen analyser (FP-628 Leco Instrument; Leco 
Corporation, St Joseph, Michigan, USA) based on the combustion principle (N x 5.83). Ash content was measured according to the AOAC method No 923.03 (AOAC., 2000). Total carbohydrate was calculated by difference, i.e. the sum of $\%$ proximate composition of constituents subtracted from the weight of the dried BSG (100\%). Total dietary fibre analysis was conducted on freeze dried BSG samples using an $\mathrm{ANKOM}^{\mathrm{TM}}$ automated dietary fibre analyser in accordance with the AOAC method 991.43 (AOAC., 1990). Mixed linkage $\beta$-glucan [(1-3),(1-4)- $\beta$-D-glucan] and total starch content was analysed according to AOAC method 996.11 and 995.16, respectively using Megazyme kit (KTSTA and K-BGLU). Lignin content was determined as Klason lignin as described by Robertson, et al. (2010). All the analysis were carried out in duplicates.

\subsubsection{Crude extracts}

Filtered BSG extracts obtained after SLE and PEF pre-treatment (LBC, LBP, DBC and DBP) were analysed for their chemical composition. Total solids were determined using Sartorius MA 160 Infrared moisture analyser (Sartorius, Göttingen, Germany). Free D-glucose was analysed using the glucose oxidase peroxidase assay using Megazyme (K-GLUC) kit following the instruction (Megazyme, 2015). Total reducing sugars were measured by colorimetric assay using the 3,5dinitrosalicylic acid reagent (Miller, 1959) and total carbohydrate by Du-bois method (Masuko, Minami, Iwasaki, Majima, Nishimura, \& Lee, 2005). Total protein and starch content were determined as described in section 2.4.1. All the analysis were carried out in duplicates.

\subsection{Amino acid profile of BSG extracts}

Free amino acid (FAA) and total amino acid (TAA) were analysed by cation exchange liquid chromatography coupled with post column ninhydrin detection (McDermott, Visentin, De Marchi, Berry, Fenelon, O’Connor, et al., 2016). A Jeol JLC-500/V AminoTac ${ }^{\mathrm{TM}}$ amino acid analyser (Jeol UK Ltd., Herts, UK) fitted with a Jeol $\mathrm{Na}^{+}$high-performance cation-exchange column was used. Deproteinised samples (using 24\% (w/v) trichloroacetic acid) for FAA and acid hydrolysed samples $\left(110{ }^{\circ} \mathrm{C}\right.$ for $24 \mathrm{~h}$ with $\left.6 \mathrm{M} \mathrm{HCl}\right)$ for TAA were used. Deproteination was achieved by mixing equal volume of sample with trichloroacetic acid for $10 \mathrm{~min}$ followed by centrifugation at $14000 \mathrm{x} \mathrm{g}$ to separate the supernatant. The collected supernatant was diluted with $0.2 \mathrm{M}$ sodium citrate buffer $(\mathrm{pH}$ 2.2) to obtain approximately $250 \mathrm{nmol}$ of each amino acid residue. The samples were then diluted 
(1:2) with an internal standard (Norleucine) to a final concentration of approximately $125 \mathrm{nmol} / \mathrm{mL}$ of each amino acid residue per $20 \mu \mathrm{L}$ of injection volume. Amino acids were detected at a wavelength of $570 \mathrm{~nm}$, with the exception of proline, which was detected at $440 \mathrm{~nm}$. The results were recorded using a Minichrom $\odot$ data handling system and expressed per gram dry weight of extract (Dwe).

\subsection{Molecular weight analysis of extracts using HP-SEC-PDA and RI detectors}

Molecular weight (MW) of proteinaceous components of extracts $(20 \mathrm{mg} / \mathrm{mL})$ were determined by high performance size exclusion chromatography (HP-SEC) coupled with Photo Diode Array (PDA) detector at a wavelength of $254 \mathrm{~nm}$. A Waters Alliance 2795 Chromatography separations module (Waters Corp., Milford, USA) coupled with Waters 2996 PDA and serially connected Zorbax GF-450 $(9.4 \times 250 \mathrm{~mm}, 6 \mu \mathrm{m})$ and Zorbax GF-250 (4.6 x $250 \mathrm{~mm}, 4 \mu \mathrm{m})$ hydrophilic gel filtration columns was used. Separation was achieved using $0.1 \mathrm{M}$ Tris- $\mathrm{HCl}(\mathrm{pH} 7.0)$ as a mobile phase with an isocratic flow rate of $1.0 \mathrm{~mL} / \mathrm{min}$ for $30 \mathrm{~min}$ with $20 \mu \mathrm{L}$ injection volume. A calibration curve was prepared using albumin monomer (66 kDa), albumin dimer $(132 \mathrm{kDa})$, carbonic anhydrase (29 kDa), cytochrome c (12.4 kDa) and aprotinin $(6.5 \mathrm{kDa})$.

Molecular weights of soluble carbohydrates of extracts $(10 \mathrm{mg} / \mathrm{mL})$ were determined by HP-SEC coupled with differential refractive index detector (RID). An Agilent 1100 series chromatography system consisting of a G 1311A pump, a G1313A automatic sample injector, guard column (SB-G 6; Shodex), a gel filtration column (SB-804 HQ, Shodex) and a RI detector G1362A (Agilent 1200 series) were used. An isocratic flow rate of $0.5 \mathrm{~mL} / \mathrm{min}$ with injection volume $20 \mu \mathrm{L}$ for $30 \mathrm{~min}$ was used with a $0.1 \mathrm{M}$ Tris buffer $(\mathrm{pH}$ 8.0) as the mobile phase. The MW was determined using the calibration curve developed by plotting retention volume versus log MW using standard $\beta$-glucan polymer of MW ranging from $35 \mathrm{kDa}$ to $650 \mathrm{kDa}$.

Furthermore the low MW fractions collected from the HP-SEC-RID were subjected to matrix-assisted laser desorption-quadrupole-time-of-flight (MALDI-Q-ToF) mass spectrometry for determination of degree of polymerisation. Briefly the fractions were mixed with saturated solution of 2,5 dihydrobenzoic acid in equal volumes. $1 \mu \mathrm{L}$ of the matrix-analyte mixture was co-crystallised on a stainless steel MALDI target plate, which were subjected to pulsed laser (337 nm) desorption and 
ionisation. Positive ion mass spectra were acquired on a MALDI-Q-ToF Premier (Waters Corp., Milford, MA, USA) for the $m / z$ range $100-1500$.

\subsection{Phenolic content and antioxidant activity}

The total phenolic content (TPC) of extracts was estimated by a colorimetric assay using the FolinCiocalteu reagent described by Singleton and Rossi (1965) with some modifications adapted for use in a 96-well micro plate. Gallic acid solution of different concentrations $(10-100 \mu \mathrm{g} / \mathrm{mL})$ were used as a reference standard to prepare calibration curve, and the results were expressed as gallic acid equivalent per gram dry weight extract (GAE/g Dwe) of BSG. Phenolic analysis was carried out in duplicates.

The 2,2-diphenyl-1-picrylhydrazyl (DPPH) radical scavenging activity assay was performed in 96well plate as described by Goupy, Hugues, Boivin, and Amiot (1999). Trolox concentrations (1-8 $\mu \mathrm{g} / \mathrm{mL}$ ) were used as a reference standard and results were expressed as trolox equivalents per gram dry weight extract (TE/g Dwe). The DPPH assay was carried out in duplicates.

Measurements of ferric reducing antioxidant power (FRAP) of the various BSG extracts were carried out based on the procedure of Stratil, Klejdus, and Kubáň (2006). A calibration curve was created with a set of standard trolox concentrations $(25-150 \mu \mathrm{g} / \mathrm{mL})$ and results were expressed as TE/g Dwe. The FRAP assay was carried out in duplicates.

Individual phenolic compounds in light and dark BSG extracts including free and bound phenolics were analysed using an Acquity ultra-high performance liquid chromatography tandem mass spectrometry (UPLC-MS/MS) (Waters Corp., MA, USA). Free phenolics were extracted with 80\% methanol followed by bound phenolics extraction on the residue using protocol described by $\mathrm{Yu}$, Vasanthan, and Temelli (2001). UPLC-MS/MS method developed by Kumari, Tiwari, Hossain, Rai, and Brunton, (2017) was adapted for identification of phenolics in BSG extracts. Briefly, filtered extracts were screened using multiple reaction monitoring transitions of 55 known polyphenols from an 'in-house' database. HSS T3 column $(\mathrm{C} 18,2.1 \times 100 \mathrm{~mm}, 1.8 \mu \mathrm{m})$ with $0.1 \%$ formic acid in water (solvent $\mathrm{A}$ ) and $0.1 \%$ formic acid in acetonitrile (solvent $\mathrm{B}$ ) through following gradient flow: $0-1 \mathrm{~min}$, $2 \% \mathrm{~B} ; 1-2.5 \mathrm{~min}, 10 \% \mathrm{~B} ; 2.5-6 \mathrm{~min}, 15 \% \mathrm{~B}$; 6-7.5 $\min , 50 \% \mathrm{~B} ; 7.5-9.5 \mathrm{~min}, 98 \% \mathrm{~B}$ and $9.5-10 \mathrm{~min}$, $2 \% \mathrm{~B}$ at a rate of $0.5 \mathrm{~mL} / \mathrm{min}$ was used to separate the analytes. The UPLC-MS/MS data were 
acquired using electrospray ionisation in negative ion mode (ESI-) with following ionisation conditions: capillary voltage $3 \mathrm{kV}$, cone voltage $30 \mathrm{~V}$, extractor voltage $3 \mathrm{~V}$, source temperature 120 ${ }^{\circ} \mathrm{C}$, and desolvation temperature $250{ }^{\circ} \mathrm{C}$. The analysis was carried out in duplicates.

\subsection{Antimicrobial activity assay}

\subsubsection{Bacterial strains and cultures}

The microorganisms used in this study to determine the antimicrobial activity of BSG extracts included four pathogenic bacterial species: two Gram-positive (Staphylococcus aureus NCTC 8178 and Listeria monocytogenes NCTC 11994), and two Gram-negative (Escherichia coli DSM 1103 and Salmonella typhimurium SARB 69). The stored strains (on ceramic beads in glycerol at $-80{ }^{\circ} \mathrm{C}$ ) were activated by streaking a single bead of each strain onto a Nutrient Agar plate followed by incubation at $37^{\circ} \mathrm{C}$ for $18 \mathrm{~h}$. A single colony from each plate was inoculated in $25 \mathrm{~mL}$ of sterile Mueller-Hinton Broth (MHB) and incubated at $37^{\circ} \mathrm{C}$ for $18 \mathrm{~h}$. The aliquots were then diluted appropriately using sterile MHB to obtain a solution containing $1 \times 10^{6} \mathrm{CFU} / \mathrm{mL}$. The cell numbers were confirmed by plate counting method after incubation at $37^{\circ} \mathrm{C}$ for $24 \mathrm{~h}$ onto plate count agar.

\subsubsection{Minimum inhibitory concentrations (MICs) determination}

The MICs of BSG crude extracts were estimated according to a 96 well microtitre plate method adapted from a previously described method (Kenny, Smyth, Walsh, Kelleher, Hewage, \& Brunton, 2014). Iodonitrotetrazolium chloride (INT, $0.2 \mathrm{mg} / \mathrm{mL}$ ) dye producing a stable pink colour ( $40 \mu \mathrm{L}$ of INT with incubation for $1 \mathrm{~h}$ at $37^{\circ} \mathrm{C}$ ) as an indicator to microbial growth was used to identify microbial activity. All PEF pre-treated and control extracts were first screened without dilution against the bacterial culture to determine its inhibition ability. The extracts showing inhibition (no pink colour development) were further selected for MIC determination. The extracts were serially diluted in a 96-well microtitre plate and incubated at $37^{\circ} \mathrm{C}$ for $24 \mathrm{~h}$ in a shaking incubator after inoculating with $100 \mu \mathrm{L}$ of bacterial suspension followed by addition of $100 \mu \mathrm{L}$ INT. The MIC of each extract against a bacterial strain was determined as the lowest sample concentration at which no pink colour development occurred. 


\subsection{Immunomodulatory activity}

\subsubsection{Human Whole Blood Assay}

Human whole blood culture assay was performed on BSG extracts as described by Gill, et al. (2016) with some modifications. Preservative free heparinised whole blood (within $30 \mathrm{~min}$ of collection from two donors) was diluted 10 times with L-glutamine-supplemented RPMI 1640 cell culture medium. The freeze dried BSG extracts (in duplicates) were reconstituted at a concentration of $10 \mathrm{mg} / \mathrm{mL}$ with RPMI 1640 media. The appropriately diluted blood was mixed with different BSG extracts (LBC, LBP, DBC, DBP) to give a final concentration of $10 \mu \mathrm{g} / \mathrm{mL}$ and incubated in a 24 -well plate at $37{ }^{\circ} \mathrm{C}$, $5 \% \mathrm{CO}_{2}$ and $96 \% \mathrm{RH}$ for two incubation time combinations i.e. $6 \mathrm{~h}$ and $24 \mathrm{~h}$. Lipopolysaccharide (LPS) at $1 \mathrm{ng} / \mathrm{mL}$ (termed as 'LPS-1ng') was used as positive control and RPMI 1640 medium alone was termed as 'control'. Cultured blood was collected in sterile, endotoxin-free polypropylene tubes and subjected to centrifugation for 10 minutes at $9000 \mathrm{x}$ g. Cell-free supernatants were harvested, transferred to vials and stored at $-80{ }^{\circ} \mathrm{C}$ prior to cytokine analysis.

\subsubsection{Immunomodulatory biomarkers (cytokine and chemokine) analysis}

Levels of pro-inflammatory cytokines: interleukin-1 beta (IL-1ß), interleukin-6 (IL-6), and tumour necrosis factor-alpha (TNF- $\alpha$ ) and chemokines: interleukin-8 (IL-8), monocyte chemotactic protein-1 (MCP-1) and macrophage inflammatory protein-1-alpha (MIP-1 $\alpha$ ), were measured in the culture supernatants by enzyme linked immune-sorbent assay (ELISA) by following manufacturer's instructions (Bio-Techne Ltd, Abingdon, UK) with minor modifications. In brief, supernatants or known standards were incubated overnight at $2-8{ }^{\circ} \mathrm{C}$ on the primary antibody coated ELISA plates. Concentrations of different analytes were determined by comparing with the generated standard curves from the known standards. Levels of all the cytokines and chemokines in the supernatants were quantified using three biological replicates of the human whole blood culture.

\subsection{Statistical analysis}

Analysis of variance was carried out using SAS, USA Version 9.3 statistical software. Statistical tests of immunomodulatory biomarkers were performed using GraphPad Prism (version 6, GraphPad Software Inc., La Jolla, CA, USA) and the statistical comparisons are detailed in supplementary

\section{Table S2.}




\section{Results and discussion}

\subsection{Compositional analysis of raw BSGs}

The proximate composition of BSG samples, summarised in supplementary Table S1, were expressed on dry weight (DW) basis except for moisture content. Moisture contents in fresh dark and light BSG samples were $70 \%$ and $75 \%$, respectively. Light BSG samples had significantly higher $(\mathrm{p}<0.05)$ contents of total carbohydrate, ash, starch, $\beta$-glucan and dietary fibre compared to dark BSG. However, the protein $(\sim 20 \%)$ and lignin $(\sim 1.5 \%)$ contents in light BSG were significantly lower than dark BSG. Results indicated that the major component of BSG is carbohydrate, ranging between 68$72 \%$ followed by protein (range $20-22 \%$ ) and fat ( 4-6\%). Total dietary fibre and starch content was in the range of $\sim 30-55 \%$ and $6-11 \%$, respectively. The obtained BSG macro-nutrient profiles were within the range of previously reported studies for BSG samples from different breweries (Robertson, et al., 2010; Waters, Jacob, Titze, Arendt, \& Zannini, 2012). However, Connolly, Piggott, and FitzGerald (2013) reported higher fat ( 10-14\%), lignin ( 23\%) and lower starch (0.85 to $1.5 \%)$ content than the present study. The reasons for such variations in the composition of BSG may be attributed to the processing conditions (malting and mashing) of the breweries, variety, growing conditions and harvesting time of the barley, type and proportion of added cereal grains and adjuncts (Mussatto, Dragone, \& Roberto, 2006). Robertson, et al. (2010) noted that while starch content was lower, the protein content was higher in BSG samples from lager producing breweries compared to breweries producing ale beer. This might be due to the fact that the lager malts are produced from a high protein containing barley varieties. The higher content of starch in BSG is an indication of inefficient brewing process, showing requirement for process improvement by breweries. Additionally, BSG powders containing a high amount of total dietary fibre could serve as an attractive and sustainable source of dietary fibre.

\subsection{Characterisation of light and dark BSG extracts}

\subsubsection{Effect of PEF pre-treatment on chemical characteristics of BSG extracts}

The composition of extracts from BSG pre-treated with PEF and control BSG (LBP, LBC, DBP and DBC) are shown in Table 1. Total extraction yield, total carbohydrate, reducing sugar and free glucose were significantly higher in LBC than DBC $(\mathrm{p}<0.05)$. On the other hand, significantly higher 
starch and protein content was exhibited by the DBP. Piggott, Connolly, and FitzGerald (2014) have also reported that protein content was higher in black compared to the pale BSG extract and carbohydrate was higher in pale compared to the black BSG extract. The almost ten-fold lower level of reducing sugar in dark BSG extracts (4.12\% DW of DBC compared to $52.66 \%$ DW of LBC) is a consequence of non-enzymatic browning reactions (Maillard reactions) which take place during the kilning process in which reducing sugars react with proteins or free amino group to form dark coloured melanoidins compounds (Wang, Qian, \& Yao, 2011).

PEF pre-treatment significantly increased $(\mathrm{p}<0.05)$ the extraction yields of protein and reducing sugars for both the BSG samples compared to untreated samples, however no significant effect was noted for total extraction yield compared to untreated samples. The higher protein content in the PEF treated samples may be due to the enhanced extraction of non-proteinaceous nitrogen components such as nucleotides aused by cell distruption. PEF pre-treatment resulted into considerably higher amount of total carbohydrate and starch in case of dark BSG extracts however no effect was observed for light BSG samples. To the best of authors' knowledge, no study exists on application of PEF in the extraction of biomolecules from light and dark BSGs. Nevertheless a study on papaya seeds, Parniakov, Rosello-Soto, Barba, Grimi, Lebovka, and Vorobiev (2015) reported enhanced recovery of proteins (2 fold) and carbohydrates (12.5\%) with PEF pre-treatment (@13.3 kV/cm field strength, 300 pulses of $2 \mathrm{~s}$ width) followed by aqueous extraction at $50{ }^{\circ} \mathrm{C}$ for $3 \mathrm{~h}$ compared to untreated seeds. Free D-glucose level was not significantly different between treated and untreated dark BSG extracts, but the PEF pre-treated light BSG extract had significantly $(\mathrm{p}<0.05)$ lower level of free D-glucose than the control.

\subsubsection{Effect of PEF pre-treatment on the amino acid profile of BSG extracts}

Total and free amino acid profiles of BSG extracts are shown in Figures 1a and b. The total amino acids (TAA) in LBC, LBP, DBC and DBP extracts were 77.31, 83.67, 65.61 and $52.36 \mathrm{mg} / \mathrm{g}$ Dwe respectively. The total free amino acids (FAA) content in LBC, LBP, DBC and DBP extracts were 23.99, 27.78, 1.16 and $1.24 \mathrm{mg} / \mathrm{g}$ Dwe constituting 31.03, 33.21, 1.77 and $2.38 \%$ of TAA respectively. It was observed that light BSG extracts had significantly higher $(\mathrm{p}<0.05)$ level of FAA compared to dark BSG; however the difference was not significant for TAA. PEF treatment resulted 
in increases of 15.83 and $7.46 \%$ increase in FAA for LBP and DBP, respectively and $8.22 \%$ increase in TAA for LBP compared to control. However a $20.2 \%$ reduction in TAA content of DBP was noted following PEF pre-treatment. This reduction in TAA in the PEF treated dark BSG extract may be attributed to the enhanced Maillard reaction (due to pre-existing Maillard intermediaries) being triggered by PEF treatments (Guan, Wang, Yu, Zeng, Han, \& Liu, 2010; Wang et al., 2011). The authors reported how glycin and arginine are involved in interactions with carbohydrate molecules due to PEF treatments, thus retarding the extraction of amino acids. The same can be confirmed in the amino-gram of DBP where asparagine and glycin content has been reduced due to their conjugation in Maillard reaction. Another reason may be the increased accessibility of amino acids for interaction with other molecules in the matrix caused due to opening up the protein structure by the PEF treatment (Liu, Zhang, Zeng, Pan, \& Wang, 2014). FAA content in dark BSG extracts were very low and as discussed earlier in section 3.2.1, which is likely due to the Maillard reaction (a non-enzymatic browning) that converts amino acids and reducing sugars into coloured melanoidin pigments during the kilning process of dark beer making.

Glutamic acid (18.5 - $22.2 \mathrm{mg} / \mathrm{g}$ Dwe) and proline (9.8 - $11.8 \mathrm{mg} / \mathrm{g}$ Dwe) were the two most adundant non-essential amino acids present in all the BSG extracts. This is in agreement with the study of Robertson, et al. (2010) showing glutamine/glutamate followed by proline as the most abundant amino acids in BSG isolates. All essential amino acids (phenylalanine, valine, threonine, histidine, methionine, leucine, isoleucine, and lysine), except tryptophan, were present in both the BSG extracts. It was also noted that dark BSG extracts were very low in arginine, aspartate, lysine, serine and threonine content compared to light BSG extracts, which is in line with the reported amino acid profile in the literature (Connolly, Piggott, \& FitzGerald, 2013). Glutamic acid (2.74 to $3.13 \mathrm{mg} / \mathrm{g}$ Dwe) was present in the highest amount in light BSG extracts; however cysteic acid (0.90 to 0.98 $\mathrm{mg} / \mathrm{g}$ Dwe) was the most abundant amino acid in dark BSG.

\subsubsection{Molecular weight distribution}

The HP-SEC-PDA and HP-SEC-RI chromatograms of proteinaceous and polysaccharide of BSG extracts are shown in Fig. 2 (a-d) and Fig. 3 (a-d), respectively. As illustrated in Fig. 2, the main chromatographic peaks in the control displayed slightly higher MW proteinaceous biomolecules 
compared to treated extracts. For example, the peaks observed in the untreated light and dark BSG extracts corresponded to a MW of 13.7 and $18.5 \mathrm{kDa}$ respectively, whereas PEF treated samples corresponded to a MW of 13.4 and $17.9 \mathrm{kDa}$. Additionally in the case of both untreated and PEFtreated dark BSG extracts, early eluting peaks of very high molecular weights 247.6 and $247.0 \mathrm{kDa}$, respectively were observed which may possibly be due to the presence of larger glyco-protein moieties or melanoidin like compounds (Wang, Qian, \& Yao, 2011). The decrease in molecular weight of proteins (although not substantial) could be attributed to the phenomena that PEF could induce the polarisation of peptides molecule, and destroying the noncovalent bonds, such as hydrophobic interactions, electrostatic interactions, hydrogen bonds, dissociating more subunits, then leading to primary and higher structure of protein being disorganised resulting into release of free reducing amino acids and small peptides (Lin et al., 2013). In all the extracts degraded artefacts between 1.5 to $2 \mathrm{kDa}$ were observed. Although molecular mass distribution for light and dark BSG protein enriched isolates (alkali extracted) are available in literature (Connolly, Piggott, \& FitzGerald, 2013), no report for aqueous extracts with or without PEF treatment have been presented before. These authors observed that $58.8 \%$ of the pale BSG protein isolates were above $10 \mathrm{kDa}$ molecular mass, whereas approx. $86 \%$ of the black BSG proteins were below $5 \mathrm{kDa}$.

Furthermore, peaks from HP-SEC-RID (Fig. 3) showed that light BSG extracts had only low MW components (approx. $1 \mathrm{kDa}$ ) whereas dark BSG extracts had distinctly higher MW components (approx. $675 \mathrm{kDa}$ ) in addition to low MW polysaccharides (approx. $1.5 \mathrm{kDa}$ ). Measuring the degree of polymerisation of the peak containing low MW fraction using MALDI-Q-ToF showed the presence of penta-saccharides (MW $828 \mathrm{Da}$ ). This may be releated to the higher heat treatment processing step (kilning) involved in dark beer manufacturing which reduces the activity of $\beta$-glucanase leading to higher MW polymer in dark BSG compared to light BSG (Gangopadhyay, Hossain, Rai, \& Brunton, 2015).

\subsubsection{Characterisation of phenolic compounds}

UPLC-MS/MS data revealed that $p$-coumaric acid and caffeic acid were the main phenolic compounds present in both light and dark BSG bound phenolic extracts, and only caffeic acid was identified as free phenolic in methanolic extract. Moreover, all the aqueous extracts (control and PEF 
treated) had polyphenols at levels below the detection limit for the assay (data not shown) and none of the extracts showed presence of ferulic acid. Similar observations have been previously made on the presence of coumaric acid (Mussatto, Dragone, \& Roberto, 2006) and absence of ferulic acid in BSG extracts (McCarthy, O'Callaghan, Connolly, Piggott, FitzGerald, \& O’Brien, 2012). Moreover, Leitao, et al. (2012) in a study on the fate of phenolics during brewing, concluded that the brewing process especially the malting step exhaustively extracts phenolic compounds from the grain leading to negligent amount of soluble phenolics in the spent grain.

\subsection{Bioactivities of BSG extracts}

\subsubsection{Total phenolics and antioxidant activity}

The TPC of dark and light BSG control extracts were found to be $4.88 \pm 0.59$ and $0.83 \pm 0.01 \mathrm{mg}$ GAE/g Dwe, respectively (Table 2 ). The significantly $(\mathrm{p}<0.05)$ lower concentration of TPC in light BSG extracts may indicate that free phenolics are less abundant in light BSG, possibly either due to degradation and/or extraction during fermentation or due to their cell bound nature. Furthermore, no significant difference between PEF treated and untreated BSG extracts were observed. This is in contrast with findings reported by Carbonell-Capella et al. (2017), where PEF pre-treament at 20 $\mathrm{kv} / \mathrm{cm}$ field intensity caused the enhancement of total phenolic content and antioxidant capacity in Stevia aqueous extracts. Already dis-integrated BSG substrates due to intensive brewing processes or lower intensity of PEF may have resulted in lower TPC recovery. The enhanced phenolics recovery from various plant by-products through PEF application have also been reviewed elsewhere (Kumari, Tiwari, Hossain, Brunton, \& Rai, 2017).

Similar to TPC, dark BSG crude extracts had significantly higher $(\mathrm{p}<0.05)$ antioxidant activities compared to light BSG extracts (Table 2). The level of FRAP and DPPH radical scavenging activity in dark BSG was found to be 8 and 9 times higher than light BSG, respectively. The trend is in agreement with the previously published data showing 5-6 times higher FRAP and 14 times higher DPPH activity in the dark BSG aqueous extracts than the light BSG extracts (Connolly, Piggott, \& FitzGerald, 2013; McCarthy, O'Callaghan, Connolly, Piggott, FitzGerald, \& O’Brien, 2012). Since presence of phenolic compounds could not be asserted by UPLC-MS/MS data, it can be inferred that this higher antioxidative activity of dark BSG extracts may be due to the presence of brown coloured 
melanoidin like molecules, formed during Maillard reaction, possessing anti-oxidant activity (Tagliazucchi, Verzelloni, \& Conte, 2010). Furthermore, no significant difference was observed between PEF treated and untreated extracts for both the BSG samples. This finding is in line with the TPC results of the current work, however, literature data does suggest improved DPPH activity in the PEF treated orange peel extracts $(92 \%$ at $3 \mathrm{kV} / \mathrm{cm}$ and $192 \%$ at $7 \mathrm{kV} / \mathrm{cm}$ field strength) (Luengo, Álvarez, \& Raso, 2013). A good correlation $\left(r^{2}=0.982\right)$ was observed between total phenolic content and antioxidant activity which underlines the veracity of the observed non-significance of the PEF treatment.

\subsubsection{Antimicrobial activity}

The undiluted PEF treated and untreated BSG extracts were screened as described in section 2.8.2 for their growth inhibition capacity against both Gram positive and Gram negative bacterial strains. Since none of the dark BSG extracts showed inhibition of bacterial cell growth (pink colour development could not be detected), these were not included for MIC determination. One probable reason of the lack of detectable pink colour development after application of dark BSG extracts could be the intense colour of the dark BSG extracts itself which masks the developed pink colour thus making it difficult to record the growth of the bacterial cells. However, some alternative method such as MTT dye assay may be recommended for determining the antimicrobial properties of dark BSG extracts where a water-soluble yellow dye i.e. 3-(4,5-dimethylthiazol-2-yl)-2,5-diphenyl tetrazolium bromide (MTT) is used (Wang, Cheng, Wang, Wei, \& Wang, 2010). Application of PEF treated light BSG extracts resulted in higher inhibition of growth for Salmonella typhimurium and Listeria monocytogenes with an MIC value of 50 and $25 \mathrm{mg} / \mathrm{mL}$, respectively compared to the untreated extracts where the value was greater than $50 \mathrm{mg} / \mathrm{mL}$. The lowest MIC value of $1.56 \mathrm{mg} / \mathrm{mL}$ was recorded for Staphylococcus aureus with no difference between control and treated extracts. However, in the case of Escherichia coli, PEF treated extracts had higher MIC value $(6.25 \mathrm{mg} / \mathrm{mL})$ compared to control $(3.13 \mathrm{mg} / \mathrm{mL})$. The higher phenolic content and antioxidant activity of PEF extracts may be the reason for the enhanced antimicrobial efficacy of these extracts as many phenolic compounds have been shown to possess antimicrobial properties (Kenny, Smyth, Walsh, Kelleher, Hewage, \& Brunton, 2014). This is the first study reporting antimicrobial activity of BSG extracts except against $S$. aureus although $\mathrm{Li}$, 
Zong, Zhang, Wei, Huang, and Luo (2013) have reported the antibacterial activity of BSG peptides against Staph. aureus.

\subsubsection{Immunomodulatory activity}

The immunomodulatory potentials of crude extracts from light and dark BSG were determined by measuring their effect on the production of pro-inflammatory cytokines and chemokines in human whole blood culture. It is well known that regulation of immune system is mediated by chemical messenger called cytokines. These are low MW soluble glycoproteins which are produced by the activated T-cells of immune system. Cytokines levels can thus serve as biomarkers of the immunity modulation induced by a compound (Coico \& Sunshine, 2015). The effect of BSG extracts on the production of cytokine and chemokine biomarkers after $6 \mathrm{~h}$ and $24 \mathrm{~h}$ of incubation in a human whole blood assay ex-vivo system is presented in Fig. 4. All the BSG extracts induced the release of significant amounts $(\mathrm{p}<0.05)$ of pro-inflammatory cytokines (IL-1 $\beta$, IL-6, TNF- $\alpha$ ) and chemokines (IL-8, MCP-1 and MIP-1 $\alpha$ ) compared to negative control (Table S2). Light BSG extracts proved to be significantly $(\mathrm{p}<0.05)$ better immune system stimulators than dark BSG extracts except in the case of MCP-1 stimulation.

Although there is previously published evidence for the immunomodulatory activity of phenolic acids such as p-coumaric acid, chlorogenic acid and ferulic acid (McCarthy, O'Callaghan, Piggott, FitzGerald, \& O'Brien, 2013), the exhibited immunomodulation by BSG extracts could not be attributed to phenolic compounds due to their absence in the extracts. However, another important component i.e. water soluble polysaccharides and polysaccharide-protein complexes have exhibited immunomodulatory activity (Ooi \& Liu, 2000) and thus could account for the immunomodulation activity of the extracts. This fact also supports the findings that light BSG extracts have higher immunomodulatory activity due the presence of higher amount of total carbohydrate and reducing sugars compared to dark BSG extracts.

PEF pre-treated light $\mathrm{BSG}$ extracts had no significant effect $(\mathrm{p}<0.05)$ on stimulation of immunomodulatory markers even after $24 \mathrm{~h}$ incubation compared to untreated samples. However, PEF pre-treated dark BSG extracts showed significantly lower $(\mathrm{p}<0.05)$ response for cytokines and 
chemokines production compared to the untreated extracts except MCP-1 stimulation where no significant difference was observed. In summary BSG extracts induced the secretion of proinflammatory cytokines especially light BSG, however PEF pre-treatments did not show positive effect in extraction of immunomodulatory components.

\section{Conclusions}

PEF assisted extraction showed significant effect on the levels of phenolics, amino acids and proteins especially in case of light BSG. Dark BSG extracts had very low levels of reducing sugars and total free amino acids. All the essential amino acids except tryptophan were present in both the BSG extracts. Molecular weight analysis revealed that the extracts are dominated by large molecules (> 13 $\mathrm{kDa}$ ) along with minor fractions possessing 1-1.5 $\mathrm{kDa}$ molecules. The presence of penta-saccharides in the lower MW peak was confirmed using MALDI-Q-ToF mass spectrometry. Aqueous extracts of BSGs showed antioxidative, antimicrobial and immunomodulatory activities. Dark BSG extracts had higher phenolic content and hence higher antioxidant activity than the light BSG. In contrast light BSG extracts showed better antimicrobial and immunomodulatory activities than the dark BSG extracts. PEF pretreated light BSG extracts showed higher antimicrobial activity against Salmonella typhimurium and Listeria monocytogenes compared to the untreated extracts with lowest MIC value of $1.56 \mathrm{mg} / \mathrm{mL}$ against Staphylococcus aureus. All the BSG extracts induced the release of significant amounts $(\mathrm{p}<0.05)$ of pro-inflammatory cytokines (IL-1 $\beta$, IL-6, TNF- $\alpha$ ) and chemokines (IL-8, MCP-1 and MIP-1 $\alpha$ ) compared to negative control. Light BSG extracts proved to be significantly $(\mathrm{p}<0.05)$ better immune system stimulators than dark BSG extracts except in the case of MCP-1 stimulation. The main phenolic compounds identified in bound and free extracts were $p$-coumaric acid and caffeic acid; however no phenolic compounds could be detected in the aqueous extracts.

\section{Funding source and role}

The authors acknowledge financial support from the 'NovTechIng' project funded under the Food Institutional Research Measure (Project No. FIRM/11/F/050) by the Irish Department of Agriculture, Food and Marine. The sponsors had no role in study design, collection, analysis and interpretation of data, writing of the report and decision to submit for publication. The immunomodulatory study was 
performed using funding from the European Union's Horizon 2020 research and innovation programme under grant agreement No 634086 (NEPHSTROM). TPG is funded by a Hardiman Research Scholarship from the College of Medicine, Nursing and Health Sciences, National University of Ireland, Galway. The materials presented and views expressed here are the responsibility of the author(s) only. The EU Commission takes no responsibility for any use made of the information set out.

\section{Conflict of interests}

The authors declare no conflict of interests.

\section{References}

AOAC. (1990) Official Methods of Analysis 15 ed.). Arlington, Virginia, USA Association of Official Analytical Chemists, Inc.

AOAC. (2000) Official Methods of Analysis of AOAC International 17 ed.). Gaithersburg, MD, USA: AOAC International.

Barba, F. J., Parniakov, O., Pereira, S. A., Wiktor, A., Grimi, N., Boussetta, N., Saraiva, J. A., Raso, J., Martin-Belloso, O., Witrowa-Rajchert, D., Lebovka, N. \& Vorobiev, E. 2015. Current applications and new opportunities for the use of pulsed electric fields in food science and industry. Food Research International, 77, 773-798.

Barba, F. J., Mariutti, L. R. B., Bragagnolo, N., Mercadante, A. Z., Barbosa-Cánovas, G. V. \& Orlien, V. 2017. Bioaccessibility of bioactive compounds from fruits and vegetables after thermal and nonthermal processing. Trends in Food Science \& Technology, 67, 195-206.

Bonar, A. (2014). Functional foods market is expected to grow 25\% by 2017: Leatherhead. http://www.nutraingredients.com/Markets-and-Trends/Functional-foods-market-is-expectedto-grow-25-by-2017-Leatherhead. Accessed 26.07.2018.

Boussetta, N., Soichi, E., Lanoisellé, J. L., \& Vorobiev, E. (2014). Valorization of oilseed residues: Extraction of polyphenols from flaxseed hulls by pulsed electric fields. Industrial Crops and Products, 52(0), 347-353. 
Carbonell-Capella, J. M., Šic Žlabur, J., Rimac Brnčić, S., Barba, F. J., Grimi, N., Koubaa, M.,

Brnčić, M. \& Vorobiev, E. 2017. Electrotechnologies, microwaves, and ultrasounds combined with binary mixtures of ethanol and water to extract steviol glycosides and antioxidant compounds from Stevia rebaudiana leaves. Journal of Food Processing and Preservation, 41, e13179.

Coico, R., \& Sunshine, G. (2015). Immunology: a short course: John Wiley \& Sons.

Connolly, A., Piggott, C. O., \& FitzGerald, R. J. (2013). Characterisation of protein-rich isolates and antioxidative phenolic extracts from pale and black brewers' spent grain. International Journal of Food Science \& Technology, 48(8), 1670-1681.

FAOSTAT. (2015). http://faostat3.fao.org/browse/Q/QC/E. Accessed 20.07.2018.

Farcas, A., Tofana, M., Socaci, S., Scrob, S., Salanta, L., \& Pop, C. (2013). Analysis of flavonoids in malt and brewers'spent grain by uv-vis spectrophotometry using different extraction technologies. Analele Universității din Oradea, Fascicula: Ecotoxicologie, Zootehnie şi Tehnologii de Industrie Alimentară, 12(B), 205-212.

Gangopadhyay, N., Hossain, M. B., Rai, D. K., \& Brunton, N. P. (2015). Optimisation of yield and molecular weight of $\beta$-glucan from barley flour using response surface methodology. Journal of Cereal Science, 62(0), 38-44.

Gill, S. K., Islam, N., Shaw, I., Ribeiro, A., Bradley, B., Brien, T. O., Kilcoyne, M., Ceredig, R., \& Joshi, L. (2016). Immunomodulatory effects of natural polysaccharides assessed in human whole blood culture and THP-1 cells show greater sensitivity of whole blood culture. International Immunopharmacology, 36, 315-323.

Goupy, P., Hugues, M., Boivin, P., \& Amiot, M. J. (1999). Antioxidant composition and activity of barley (Hordeum vulgare) and malt extracts and of isolated phenolic compounds. Journal of the Science of Food and Agriculture, 79(12), 1625-1634.

Guan, Y. G., Wang, J., Yu, S. J., Zeng, X. A., Han, Z. \& Liu, Y. Y. 2010. A pulsed electric field procedure for promoting Maillard reaction in an asparagine-glucose model system. International journal of food science \& technology, 45, 1303-1309. 
Kenny, O., Smyth, T. J., Walsh, D., Kelleher, C. T., Hewage, C. M., \& Brunton, N. P. (2014). Investigating the potential of under-utilised plants from the Asteraceae family as a source of natural antimicrobial and antioxidant extracts. Food Chemistry, 161, 79-86.

Kumari, B., Tiwari, B. K., Hossain, M. B., Brunton, N. P., \& Rai, D. K. (2017). Recent advances on application of ultrasound and pulsed electric field technologies in the extraction of bioactives from agro-Industrial by-products. Food and Bioprocess Technology.DOI: https://doi.org/10.1007/s11947-017-1961-9.

Kumari, B., Tiwari, B. K., Hossain, M. B., Rai, D. K., \& Brunton, N. P. (2017). Ultrasound-assisted extraction of polyphenols from potato peels: profiling and kinetic modelling. International Journal of Food Science \& Technology, 52(6), 1432-1439.

Leitao, C., Marchioni, E., Bergaentzlé, M., Zhao, M., Didierjean, L., Miesch, L., Holder, E., Miesch, M., \& Ennahar, S. (2012). Fate of polyphenols and antioxidant activity of barley throughout malting and brewing. Journal of Cereal Science, 55(3), 318-322.

Li, L., Zong, X. Y., Zhang, J., Wei, C. H., Huang, Z. G., \& Luo, H. B. (2013). Antibacterial activity of brewer's spent grains peptides to Staphylococcus aureus. Advanced Materials Research, 699, 320-325.

Lin, S., Jin, Y., Liu, M., Yang, Y., Zhang, M., Guo, Y., Jones, G., Liu, J. \& Yin, Y. J. F. C. (2013). Research on the preparation of antioxidant peptides derived from egg white with assisting of high-intensity pulsed electric field. Food Chemistry, 139, 300-306.

Liu, Y.-Y., Zhang, Y., Zeng, X.-A., El-Mashad, H., Pan, Z.-L. \& Wang, Q.-J. 2014. Effect of pulsed electric field on microstructure of some amino acid group of soy protein isolates. International journal of food engineering, 10, 113-120.

Luengo, E., Álvarez, I., \& Raso, J. (2013). Improving the pressing extraction of polyphenols of orange peel by pulsed electric fields. Innovative Food Science \& Emerging Technologies, 17(0), 79-84. 
Lynch, K. M., Steffen, E. J., \& Arendt, E. K. (2016). Brewers' spent grain: a review with an emphasis on food and health. Journal of the Institute of Brewing, 122(4), 553-568.

Marquer, P. (2010). Eurostat statistics in focus: Agriculture and fisheries. http://ec.europa.eu/eurostat/en/web/products-statistics-in-focus/-/KS-NN-03-021. Accessed 19.07.2018.

Masuko, T., Minami, A., Iwasaki, N., Majima, T., Nishimura, S.-I., \& Lee, Y. C. (2005). Carbohydrate analysis by a phenol-sulfuric acid method in microplate format. Analytical Biochemistry, 339(1), 69-72.

McCarthy, A. L., O’Callaghan, Y. C., Connolly, A., Piggott, C. O., FitzGerald, R. J., \& O’Brien, N. M. (2012). Phenolic extracts of brewers' spent grain (BSG) as functional ingredients Assessment of their DNA protective effect against oxidant-induced DNA single strand breaks in U937 cells. Food Chemistry, 134(2), 641-646.

McDermott, A., Visentin, G., De Marchi, M., Berry, D. P., Fenelon, M. A., O’Connor, P. M., Kenny, O. A., \& McParland, S. (2016). Prediction of individual milk proteins including free amino acids in bovine milk using mid-infrared spectroscopy and their correlations with milk processing characteristics. Journal of Dairy Science, 99(4), 3171-3182.

Miller, G. (1959). Estimation of reducing sugars by DNSA method. Journal of Analytical Chemistry, $31,426-428$.

Moreira, M. M., Morais, S., Barros, A. A., Delerue-Matos, C., \& Guido, L. F. (2012). A novel application of microwave-assisted extraction of polyphenols from brewer's spent grain with HPLC-DAD-MS analysis. Analytical and Bioanalytical Chemistry, 403(4), 1019-1029.

Mussatto, S. I., Dragone, G., \& Roberto, I. C. (2006). Brewers' spent grain: generation, characteristics and potential applications. Journal of Cereal Science, 43(1), 1-14.

Ooi, V. E., \& Liu, F. (2000). Immunomodulation and anti-cancer activity of polysaccharide-protein complexes. Current Medicinal Chemistry, 7(7), 715-729.

Parniakov, O., Rosello-Soto, E., Barba, F. J., Grimi, N., Lebovka, N., \& Vorobiev, E. (2015). New approaches for the effective valorization of papaya seeds: Extraction of proteins, phenolic 
compounds, carbohydrates, and isothiocyanates assisted by pulsed electric energy. Food Research International, 77(0), 711-717.

Piggott, C. O., Connolly, A., \& FitzGerald, R. J. (2014). Application of ultrafiltration in the study of phenolic isolates and melanoidins from pale and black brewers' spent grain. International Journal of Food Science \& Technology, 49(10), 2252-2259.

Puértolas, E. \& Barba, F. J. 2016. Electrotechnologies applied to valorization of by-products from food industry: Main findings, energy and economic cost of their industrialization. Food and Bioproducts Processing, 100, 172-184.

Puértolas, E., Koubaa, M. \& Barba, F. J. 2016. An overview of the impact of electrotechnologies for the recovery of oil and high-value compounds from vegetable oil industry: Energy and economic cost implications. Food Research International, 80, 19-26.

Reis, S. F., Coelho, E., Coimbra, M. A., \& Abu-Ghannam, N. (2015). Improved efficiency of brewer's spent grain arabinoxylans by ultrasound-assisted extraction. Ultrasonics Sonochemistry, 24, 155-164.

Robertson, J. A., I'Anson, K. J. A., Treimo, J., Faulds, C. B., Brocklehurst, T. F., Eijsink, V. G. H., \& Waldron, K. W. (2010). Profiling brewers' spent grain for composition and microbial ecology at the site of production. LWT - Food Science and Technology, 43(6), 890-896.

Singleton, V., \& Rossi, J. A. (1965). Colorimetry of total phenolics with phosphomolybdicphosphotungstic acid reagents. American Journal of Enology and Viticulture, 16(3), 144-158.

Soliva-Fortuny, R., Balasa, A., Knorr, D., \& Martín-Belloso, O. (2009). Effects of pulsed electric fields on bioactive compounds in foods: a review. Trends in Food Science \& Technology, 20(11-12), 544-556.

Stratil, P., Klejdus, B., \& Kubáň, V. (2006). Determination of total content of phenolic compounds and their antioxidant activity in vegetables: Evaluation of spectrophotometric methods. Journal of Agricultural and Food Chemistry, 54(3), 607-616. 
Tagliazucchi, D., Verzelloni, E., \& Conte, A. (2010). Effect of dietary melanoidins on lipid peroxidation during simulated gastric digestion: Their possible role in the prevention of oxidative Damage. Journal of Agricultural and Food Chemistry, 58(4), 2513-2519.

Tang, D.-S., Tian, Y.-J., He, Y.-Z., Li, L., Hu, S.-Q., \& Li, B. (2010). Optimisation of ultrasonicassisted protein extraction from brewer's spent grain. Czech Journal of Food Sciences, 28(1), 9-17.

Wang, H.-Y., Qian, H., \& Yao, W.-R. (2011). Melanoidins produced by the Maillard reaction: Structure and biological activity. Food Chemistry, 128(3), 573-584.

Wang, H., Cheng, H., Wang, F., Wei, D. \& Wang, X. 2010. An improved 3-(4, 5-dimethylthiazol-2yl)-2, 5-diphenyl tetrazolium bromide (MTT) reduction assay for evaluating the viability of Escherichia coli cells. Journal of microbiological methods, 82, 330-333.

Wang, J., Guan, Y.-G., Yu, S.-J., Zeng, X.-A., Liu, Y.-Y., Yuan, S. \& Xu, R. 2011. Study on the Maillard reaction enhanced by pulsed electric field in a glycin-glucose model system. Food and Bioprocess Technology, 4, 469-474.

Waters, D., Jacob, F., Titze, J., Arendt, E., \& Zannini, E. (2012). Fibre, protein and mineral fortification of wheat bread through milled and fermented brewer's spent grain enrichment. European Food Research and Technology, 235(5), 767-778.

Yu, J., Vasanthan, T., \& Temelli, F. (2001). Analysis of phenolic acids in barley by HighPerformance Liquid Chromatography. Journal of Agricultural and Food Chemistry, 49(9), $4352-4358$ 


\section{Figure Legends}

Figure 1: Total amino acid profile (a) and free amino acid profile (b) of PEF pre-treated and control BSG extracts; (LBC: light BSG control, LBP: light BSG PEF pre-treated, DBC: dark BSG control and DBP: dark BSG PEF pre-treated)

Figure 2: Size exclusion chromatograms of proteinaceous contents in control and PEF pre-treated BSG extracts; a) light BSG control (LBC), b) light BSG PEF treated (LBP), c) dark BSG control (DBC), and d) dark BSG PEF treated (DBP)

Figure 3: Size exclusion chromatograms of PEF pre-treated and control BSG extracts showing molecular weight polysaccharides; a) light BSG control (LBC), b) light BSG PEF pre-treated (LBP), c) dark BSG control (DBC) and d) dark BSG PEF pre-treated (DBP)

Figure 4: Levels of a) cytokines, b) chemokines production in human whole blood after $6 \mathrm{~h}$ and $24 \mathrm{~h}$ of incubation after application of BSG extracts. [Interleukin-1 beta (IL-1 $\beta$ ), interleukin-6 (IL-6), tumour necrosis factor-alpha (TNF- $\alpha$ ), interleukin-8 (IL-8), monocyte chemotactic protein-1 (MCP-1) and macrophage inflammatory protein-1-alpha (MIP-1 $\alpha$ ); LPS: Lipopolysaccharide, LBC: light BSG control, LBP: light BSG PEF pre-treated, DBC: dark BSG control and DBP: dark BSG PEF pre-treated] 


\section{Figure 1.}

a)

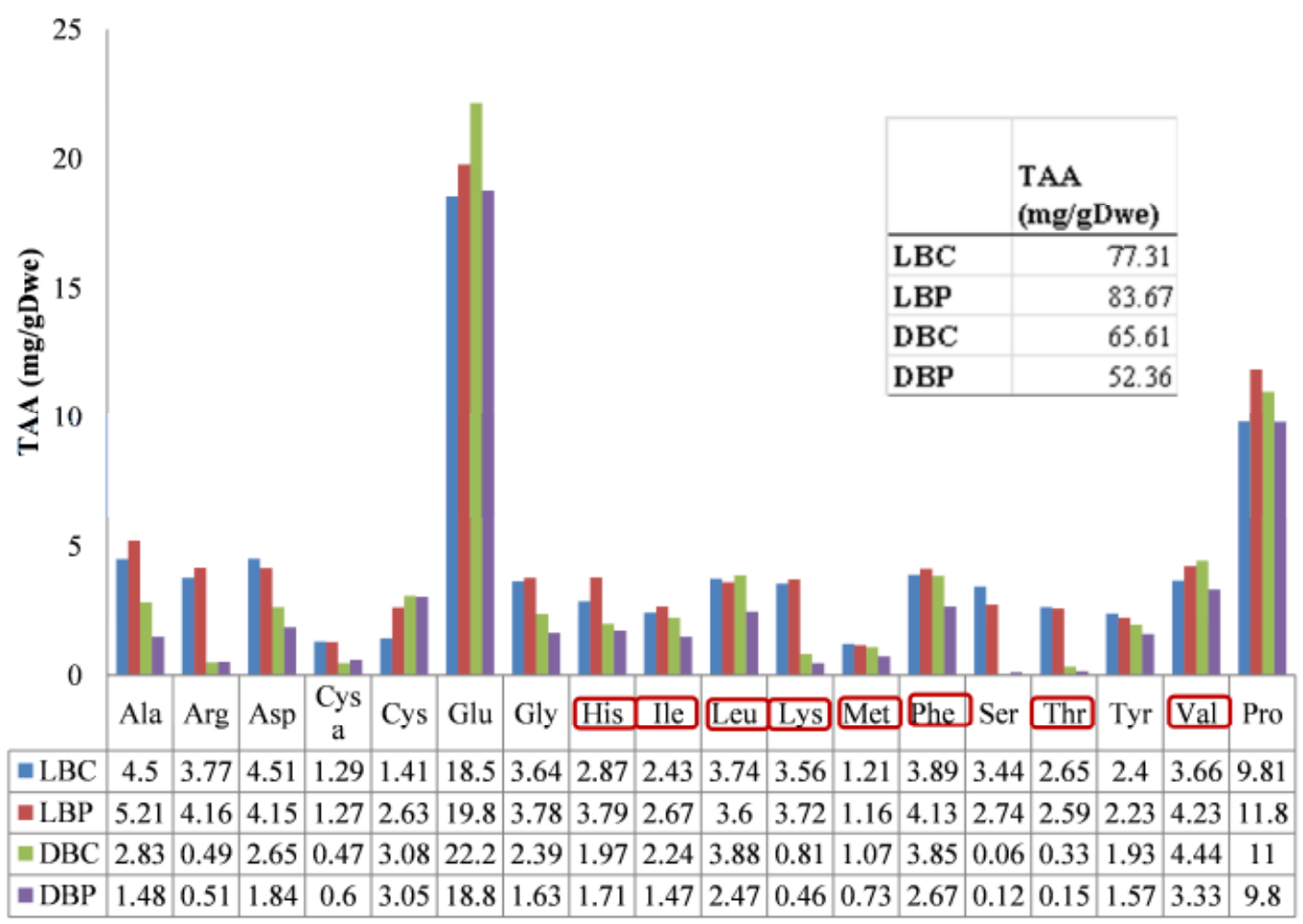

b)

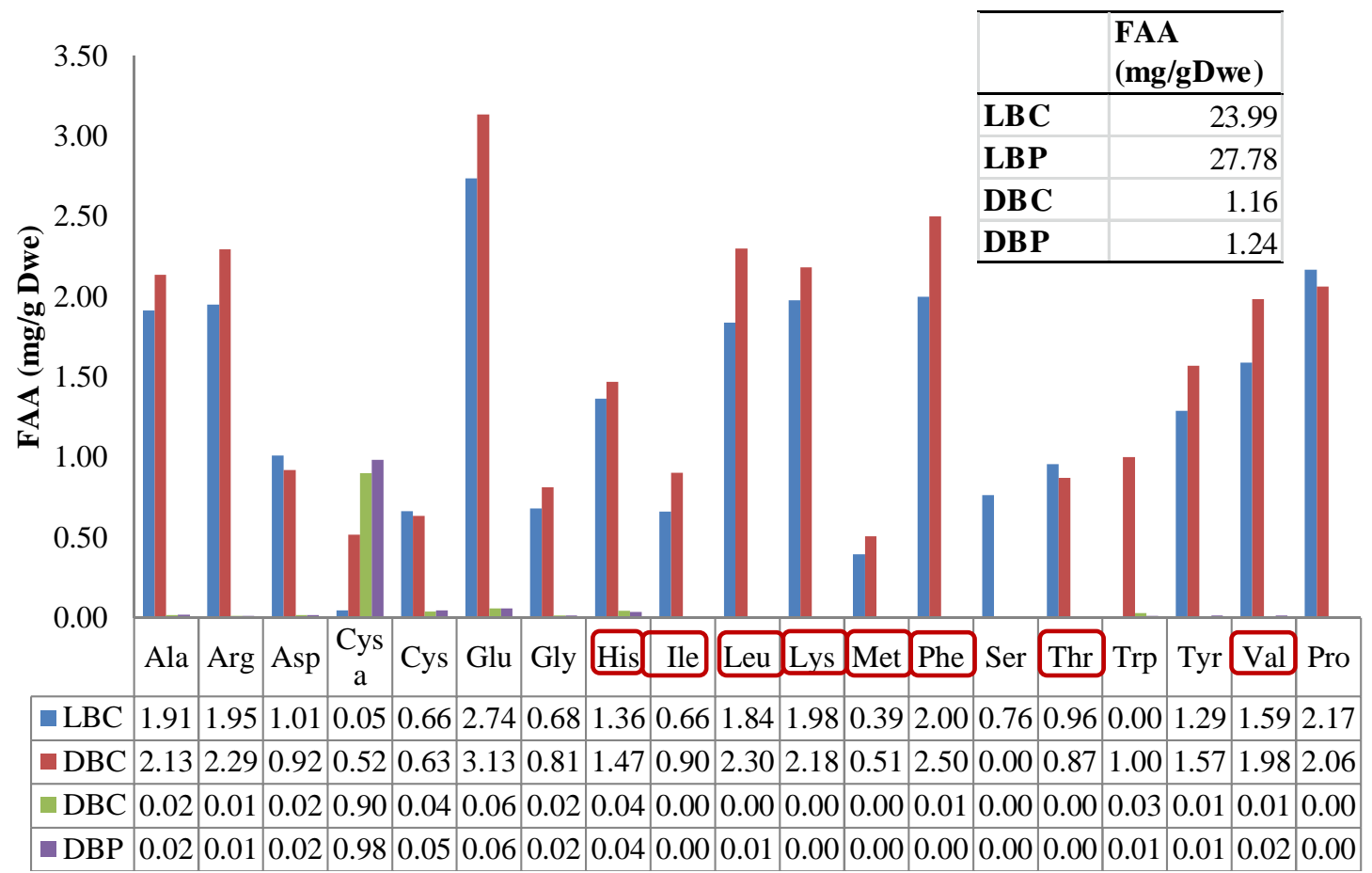

Highlighted amino acids are essential AAs 
Figure 2.

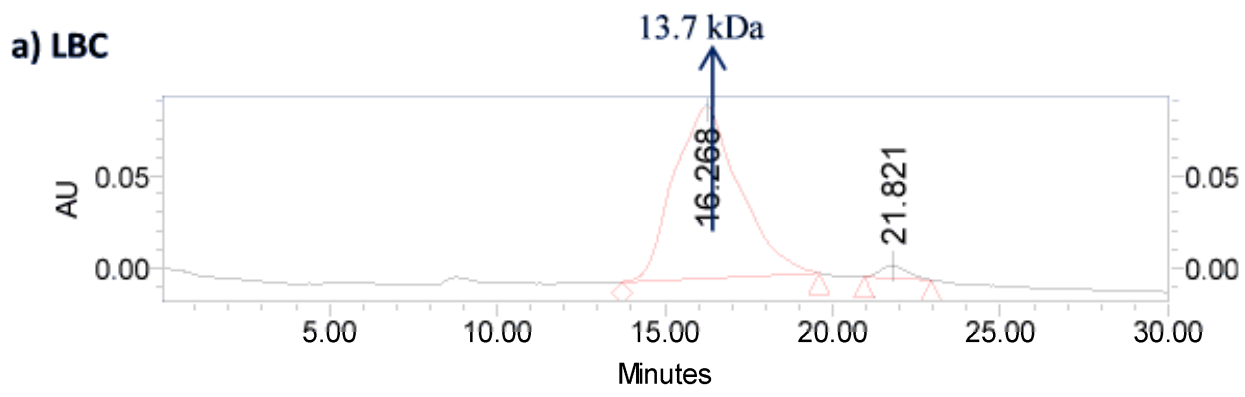

b) LBP

$13.4 \mathrm{kDa}$
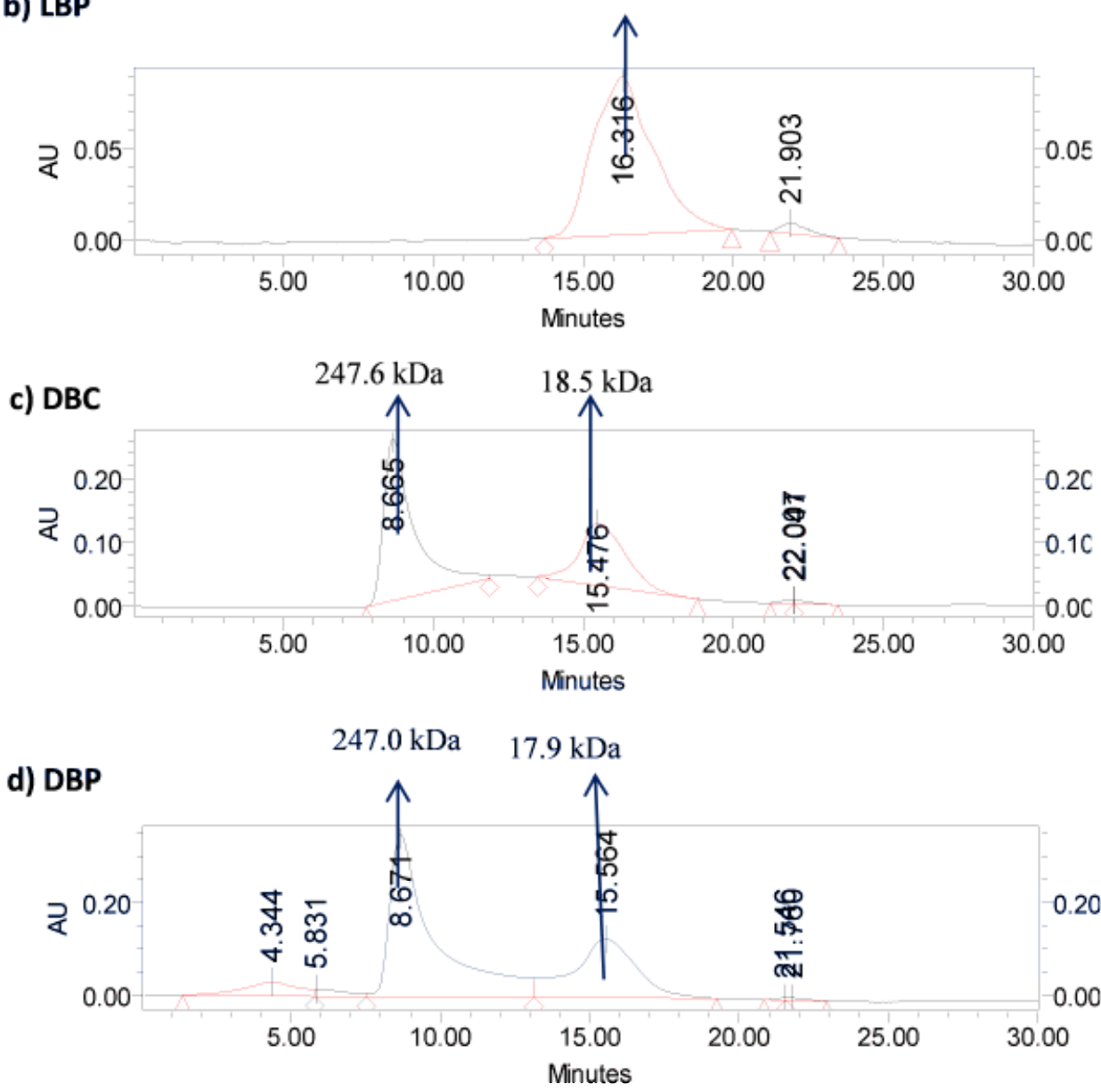
$1 \quad$ Figure 3
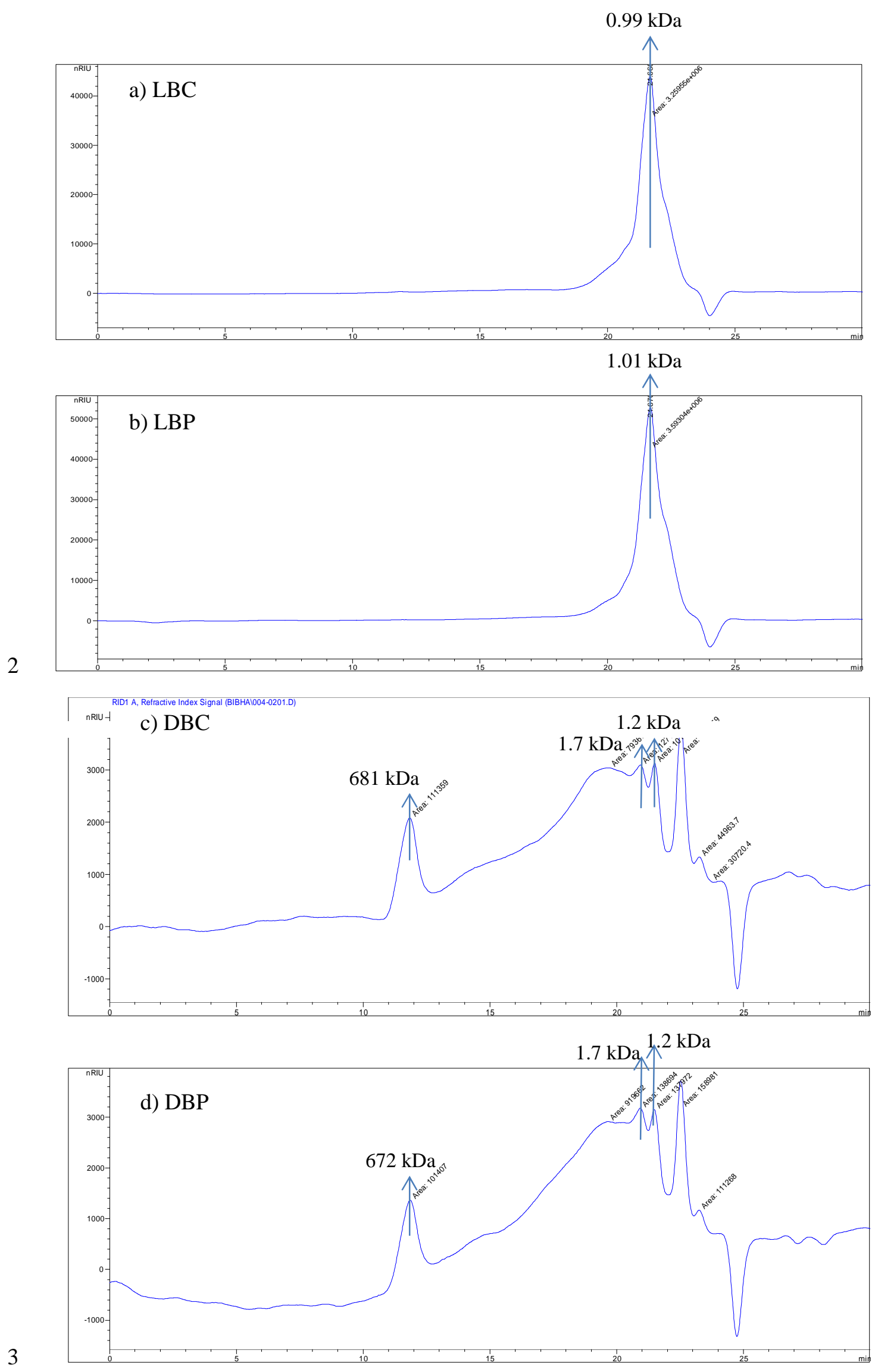
$4 \quad$ Figure 4

5 a) Cytokines
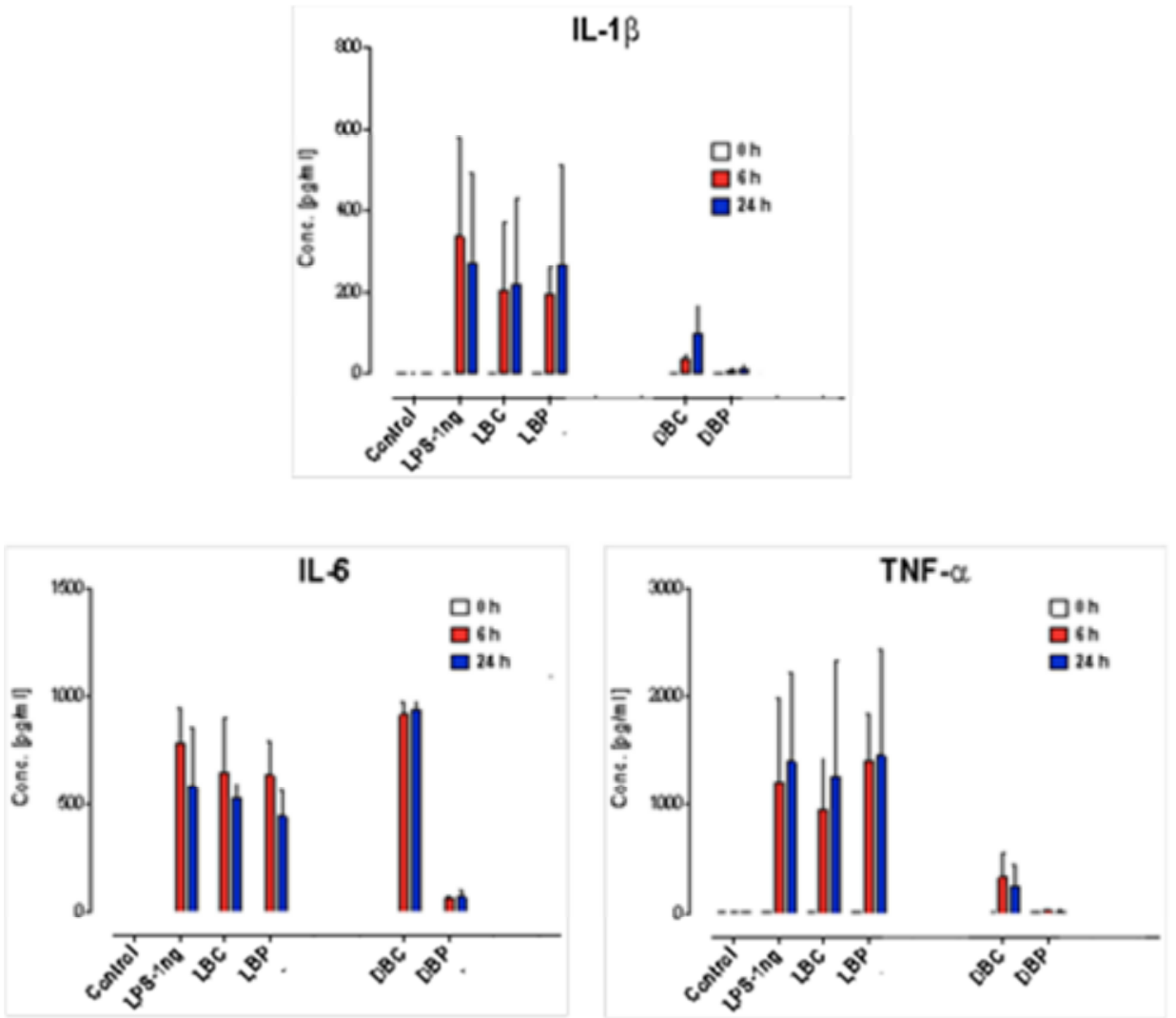

6

7

b) Chemokines
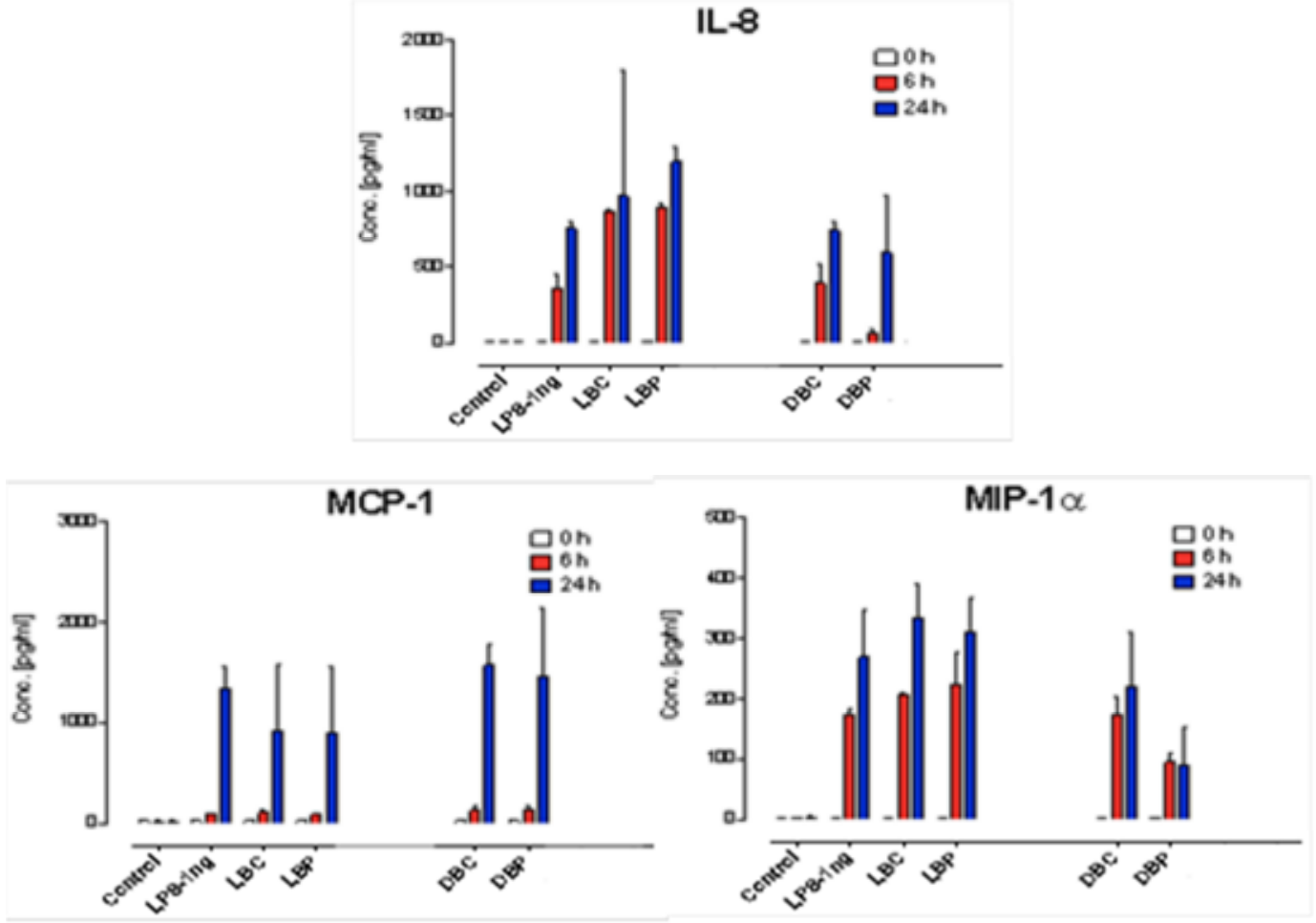


\section{Table 1}

10 Macronutrient composition of light and dark BSG extracts

\begin{tabular}{lllllll}
\hline Treatment & Yield $(\%$ & CHO $(\%$ & Protein & Starch & Red sugar & Free glucose \\
& w/w $)$ & Dwe $)$ & $(\%$ Dwe $)$ & $(\%$ Dwe $)$ & $(\%$ Dwe $)$ & $(\%$ Dwe $)$ \\
\hline LBC & $12.74^{\mathrm{a}}$ & $79.47^{\mathrm{a}}$ & $18.73^{\mathrm{c}}$ & $4.25^{\mathrm{c}}$ & $52.66^{\mathrm{b}}$ & $3.33^{\mathrm{a}}$ \\
LBP & $13.45^{\mathrm{a}}$ & $80.27^{\mathrm{a}}$ & $20.31^{\mathrm{b}}$ & $4.50^{\mathrm{c}}$ & $55.27^{\mathrm{a}}$ & $1.85^{\mathrm{b}}$ \\
DBC & $10.10^{\mathrm{b}}$ & $71.44^{\mathrm{c}}$ & $17.36^{\mathrm{d}}$ & $5.09^{\mathrm{b}}$ & $4.12^{\mathrm{d}}$ & $0.50^{\mathrm{c}}$ \\
DBP & $10.50^{\mathrm{b}}$ & $75.31^{\mathrm{b}}$ & $24.34^{\mathrm{a}}$ & $5.84^{\mathrm{a}}$ & $6.33^{\mathrm{c}}$ & $0.52^{\mathrm{c}}$ \\
\hline MSD* & 0.9177 & 1.7054 & 0.9102 & 0.406 & 1.1404 & 0.2895 \\
\hline
\end{tabular}

11 LBC: Light BSG control extract, LBP: Light BSG PEF pre-treated extract, DBC: Dark BSG control extract and

12 DBP: Dark BSG PEF pre-treated extract, Dwe: dry weight extracts

13 abcd values followed by same letter within a column are not significantly different at $p<0.05$; MSD: Minimum

14 significant difference

15 Each value is expressed as mean \pm standard deviation $(\mathrm{n}=2)$

16

17 
Table 2

19 Total phenolic and antioxidant capacity of PEF pre-treated and control extracts from light and 20 dark BSG.

\begin{tabular}{cccc}
\hline Treatment & TPC & DPPH activity & FRAP activity \\
& $(\mathbf{m g ~ G A E} / \mathbf{g}$ Dwe $)$ & $(\mathbf{m g}$ TE/g Dwe $)$ & $(\mathbf{m g}$ TE/g Dwe $)$ \\
\hline LBC & $0.83 \pm 0.01^{\mathrm{a}}$ & $0.34 \pm 0.00^{\mathrm{a}}$ & $0.81 \pm 0.03^{\mathrm{a}}$ \\
$\mathbf{L B P}$ & $1.40 \pm 0.00^{\mathrm{a}}$ & $0.48 \pm 0.03^{\mathrm{a}}$ & $1.34 \pm 0.05^{\mathrm{a}}$ \\
DBC & $4.88 \pm 0.59^{\mathrm{b}}$ & $3.38 \pm 0.15^{\mathrm{b}}$ & $10.85 \pm 1.19^{\mathrm{b}}$ \\
DBP & $3.97 \pm 0.23^{\mathrm{b}}$ & $3.18 \pm 0.01^{\mathrm{b}}$ & $9.05 \pm 0.63^{\mathrm{b}}$
\end{tabular}

21 LBC: Light BSG control extract, LBP: Light BSG PEF pre-treated extract, DBC: Dark BSG control extract and 22 DBP: Dark BSG PEF pre-treated extract, , Dwe: dry weight extracts

23 Each value is expressed as mean \pm standard deviation $(\mathrm{n}=2)$

24 Means with different letters within a column are significantly different $(p<0.05)$ 


\section{Supplementary Material}

\section{Table S1}

28 Macronutrient composition of light and dark BSG powder

\begin{tabular}{|c|c|c|}
\hline Parameters & Light BSG (\% DW) & Dark BSG (\% DW) \\
\hline Moisture $^{\#}$ & $74.54 \pm 0.25^{\mathrm{a}}$ & $69.61 \pm 0.00^{b}$ \\
\hline Crude protein & $20.12 \pm 0.19^{b}$ & $22.69 \pm 0.07^{\mathrm{a}}$ \\
\hline Crude carbohydrate* & $72.42 \pm 0.11^{\mathrm{a}}$ & $68.60 \pm 0.93^{\mathrm{b}}$ \\
\hline Fat & $4.22 \pm 0.14^{\mathrm{a}}$ & $6.75 \pm 0.98^{\mathrm{a}}$ \\
\hline Ash & $3.23 \pm 0.06^{\mathrm{a}}$ & $1.97 \pm 0.12^{\mathrm{b}}$ \\
\hline Starch & $10.91 \pm 0.12^{\mathrm{a}}$ & $6.28 \pm 0.08^{\mathrm{b}}$ \\
\hline$\beta$-glucan & $1.15 \pm 0.01^{\mathrm{a}}$ & $0.79 \pm 0.05^{\mathrm{b}}$ \\
\hline Lignin & $1.52 \pm 0.01^{\mathrm{b}}$ & $2.54 \pm 0.25^{\mathrm{a}}$ \\
\hline Total dietary fibre & $54.50 \pm 1.28^{\mathrm{a}}$ & $31.73 \pm 0.47^{b}$ \\
\hline \multicolumn{3}{|l|}{ \#Fresh weight basis } \\
\hline \multicolumn{3}{|c|}{${ }^{*}$ Measured by difference $\{\%$ Carbohydrate $=100-\%($ protein + fat + ash $)\}$} \\
\hline Each value is expressed & \pm standard deviation $(\mathrm{n}=$ & \\
\hline
\end{tabular}


34 Statistical data of two-way ANOVA and unpaired t- tests to assess the difference between the BSG treatment groups as well as the untreated control

\begin{tabular}{|c|c|c|c|c|c|c|}
\hline & \multicolumn{6}{|c|}{ Statistical Tests for Significance (p value) } \\
\hline & \multicolumn{6}{|c|}{ Unpaired T-tests } \\
\hline & IL-1及 & IL-6 & TNF $\alpha$ & IL-8 & MCP-1 & MIP1a \\
\hline \multicolumn{7}{|l|}{6 hour } \\
\hline Control vs LPS & 0.0015 & $<0.0001$ & 0.0009 & $<0.0001$ & $<0.0001$ & $<0.0001$ \\
\hline Control vs LBC & 0.0033 & $<0.0001$ & $<0.0001$ & $<0.0001$ & $<0.0001$ & $<0.0001$ \\
\hline Control vs LBP & $<0.0001$ & $<0.0001$ & $<0.0001$ & $<0.0001$ & $<0.0001$ & $<0.0001$ \\
\hline Control vs DBC & $<0.0001$ & $<0.0001$ & 0.0010 & $<0.0001$ & $<0.0001$ & $<0.0001$ \\
\hline Control vs DBP & $<0.0001$ & $<0.0001$ & 0.0006 & $<0.0001$ & $<0.0001$ & $<0.0001$ \\
\hline $\mathrm{LBC} v s \mathrm{LBP}$ & 0.8489 & 0.8744 & 0.0549 & 0.5918 & 0.1661 & 0.3641 \\
\hline $\mathrm{DBC} v s \mathrm{DBP}$ & $<0.0001$ & $<0.0001$ & 0.0013 & $<0.0001$ & 0.9578 & $<0.0001$ \\
\hline $\mathrm{LBC} v s \mathrm{DBC}$ & 0.0099 & 0.0167 & 0.0037 & $<0.0001$ & 0.2471 & 0.0394 \\
\hline LBP vs DBP & $<0.0001$ & $<0.0001$ & $<0.0001$ & $<0.0001$ & 0.0274 & $<0.0001$ \\
\hline \multicolumn{7}{|l|}{24 hour } \\
\hline Control vs LPS & 0.0035 & $<0.0001$ & 0.0004 & $<0.0001$ & $<0.0001$ & $<0.0001$ \\
\hline Control vs LBC & 0.0090 & $<0.0001$ & 0.0046 & 0.0046 & 0.0017 & $<0.0001$ \\
\hline Control vs LBP & 0.0068 & $<0.0001$ & 0.0011 & $<0.0001$ & 0.0021 & $<0.0001$ \\
\hline Control vs DBC & 0.0013 & $<0.0001$ & 0.0034 & $<0.0001$ & $<0.0001$ & $<0.0001$ \\
\hline Control vs DBP & 0.0183 & $<0.0001$ & 0.0057 & 0.0007 & $<0.0001$ & 0.0017 \\
\hline $\mathrm{LBC} v s \mathrm{LBP}$ & 0.6577 & 0.1203 & 0.6855 & 0.4196 & 0.9598 & 0.4749 \\
\hline $\mathrm{DBC} v s \mathrm{DBP}$ & 0.0030 & $<0.0001$ & 0.0042 & 0.2631 & 0.6341 & 0.0046 \\
\hline $\mathrm{LBC} v s \mathrm{DBC}$ & 0.1182 & $<0.0001$ & 0.0162 & 0.4188 & 0.0162 & 0.0114 \\
\hline LBP $v s$ DBP & 0.0086 & $<0.0001$ & 0.0011 & 0.0011 & 0.1037 & $<0.0001$ \\
\hline \multicolumn{7}{|l|}{ ANOVA } \\
\hline \multicolumn{7}{|l|}{ Oh vs $6 \mathrm{~h}$} \\
\hline Control & 0.0157035 & 0.00336044 & 0.717902 & 0.212138 & 0.963072 & 0.00470782 \\
\hline LPS-1ng & 0.00152622 & $1.338190 \mathrm{e}-007$ & 0.000857636 & $1.156297 \mathrm{e}-006$ & $8.397954 \mathrm{e}-008$ & $3.834710 \mathrm{e}-010$ \\
\hline LBC & 0.00331239 & $1.720284 \mathrm{e}-005$ & $9.267292 \mathrm{e}-005$ & $1.053335 \mathrm{e}-010$ & $1.294059 \mathrm{e}-005$ & $1.227722 \mathrm{e}-010$ \\
\hline LBP & $4.231547 \mathrm{e}-006$ & $3.848425 \mathrm{e}-007$ & $1.859621 \mathrm{e}-006$ & $1.440253 \mathrm{e}-010$ & $3.766953 \mathrm{e}-007$ & $3.179428 \mathrm{e}-007$ \\
\hline $\mathrm{DBC}$ & $1.571115 \mathrm{e}-007$ & $3.567375 \mathrm{e}-010$ & 0.000968795 & $1.978073 e-006$ & $7.903022 \mathrm{e}-005$ & $1.878065 \mathrm{e}-008$ \\
\hline DBP & $3.919209 \mathrm{e}-005$ & $4.592412 \mathrm{e}-008$ & 0.000481863 & 0.000112619 & $4.157382 \mathrm{e}-005$ & $2.578270 \mathrm{e}-008$ \\
\hline
\end{tabular}




\section{$6 \mathrm{~h} v \mathrm{24} \mathrm{h}$}

\begin{tabular}{|c|c|c|c|c|c|c|}
\hline Control & $5.150006 \mathrm{e}-006$ & 0.069046 & 0.701681 & 0.0234193 & 0.443677 & 0.0947265 \\
\hline LPS-1ng & 0.546742 & 0.0923758 & 0.605604 & $5.207884 \mathrm{e}-006$ & $4.143464 \mathrm{e}-008$ & 0.00636873 \\
\hline LBC & 0.879146 & 0.205379 & 0.441771 & 0.715432 & 0.00324453 & 0.00025042 \\
\hline LBP & 0.395818 & 0.0193148 & 0.901744 & 0.00075023 & 0.00351281 & 0.0135967 \\
\hline $\mathrm{DBC}$ & 0.0181676 & 0.683708 & 0.418269 & $5.743708 \mathrm{e}-005$ & $1.661774 \mathrm{e}-008$ & 0.179432 \\
\hline DBP & 0.238812 & 0.329024 & 0.309435 & 0.00145978 & 0.000156136 & 0.79555 \\
\hline \multicolumn{7}{|c|}{$0 \mathrm{~h} v s 24 \mathrm{~h}$} \\
\hline Control & 0.913628 & 0.782718 & 0.469603 & 0.84074 & 0.452789 & 0.00891244 \\
\hline LPS-1ng & 0.00350192 & $8.068827 e-005$ & 0.000367609 & $2.711428 \mathrm{e}-010$ & $2.554289 \mathrm{e}-008$ & $1.549350 \mathrm{e}-006$ \\
\hline LBC & 0.00902326 & $4.222741 \mathrm{e}-009$ & 0.00455499 & 0.0046331 & 0.00170752 & $3.048870 \mathrm{e}-008$ \\
\hline LBP & 0.00678004 & $6.880969 \mathrm{e}-007$ & 0.00106328 & $7.705762 \mathrm{e}-010$ & 0.00211356 & $5.683701 \mathrm{e}-008$ \\
\hline $\mathrm{DBC}$ & 0.00126976 & $1.546343 \mathrm{e}-010$ & 0.00331287 & $7.868269 \mathrm{e}-010$ & $7.109036 \mathrm{e}-009$ & $2.365530 \mathrm{e}-005$ \\
\hline DBP & 0.018228 & $3.677017 \mathrm{e}-006$ & 0.00272678 & 0.000663515 & $8.157848 \mathrm{e}-005$ & 0.00138031 \\
\hline
\end{tabular}

35 Interleukin-1 beta (IL-1 $\beta$ ), interleukin-6 (IL-6), tumour necrosis factor-alpha (TNF- $\alpha$ ), interleukin-8 (IL-8), monocyte chemotactic protein-1 (MCP-1) and macrophage

36 inflammatory protein-1-alpha (MIP-1 $\alpha)$

37 (LPS: Lipopolysaccharide, LBC: light BSG control, LBP: light BSG PEF pre-treated, DBC: dark BSG control and DBP: dark BSG PEF pre-treated) 